\title{
EFEK TINDAK LANJUT PEMERINTAH KABUPATEN MAROS TERHADAP BANGUNAN KANTOR PEKERJAAN UMUM PASCA BENCANA BANJIR 2019
}

\author{
Rahmiani Rahim*, Nuryuningsih, Mayyadah Syuaib \\ Jurusan Teknik Arsitektur \\ Fakultas Sains dan Teknologi UIN Alauddin Makassar \\ J1. Sultan Alauddin No. 63, Kabupaten Gowa, Sulawesi Selatan. 92113 \\ *E-mail: ammi.rahim23@gmail.com
}

\begin{abstract}
Abstrak: Penelitian ini bertujuan untuk mengevaluasi tindak lanjut pemerintah terhadap gedung Kantor Dinas PU Kabupaten Maros pasca bencana banjir pada Januari 2019 dengan melakukan studi pustaka, observasi dan wawancara di lapangan. Hasil penelitian menunjukkan bahwa tindak lanjut pemerintah terhadap gedung Kantor Dinas Pekerjaan Umum Maros adalah dengan menaikkan elevasi lantai dari lantai dasar menjadi kurang lebih 1 meter, hal tersebut berdampak pada pengguna gedung, salah satunya adalah berkurangnya tingkat kenyamanan. di dalam gedung karena jarak antara lantai dan plafon tidak memenuhi standar desain interior yang baik. Karena itu, selain tindakan peninggian lantai, penggunaan warna dinding dan plafon pada interior haruslah warna-warna yang dapat memberikan kesan luas dan tinggi seperti putih, meminimalkan penggunaan furnitur yang berlebihan dan berukuran besar.
\end{abstract}

Kata Kunci: banjir, interior, kenyamanan, mitigasi

\section{PENDAHULUAN}

$\mathrm{K}$

abupaten Maros pada bulan Januari 2019 mengalami bencana banjir. Hal ini disebabkan karena meluapnya air sungai sebagai akibat dari curah hujan yang begitu tinggi. Kejadian ini merupakan hal yang baru dialami oleh warga khususnya pada komplek perkantoran pemerintahan. Salah satunya adalah Kantor Dinas Pekerjaan Umum (PU) Kabupaten Maros yang juga mengalami dampak bencana banjir. Ketinggian air di dalam gedung mencapai sekitar $75 \mathrm{~cm}$. Kejadian ini berdampak pada kinerja pegawai pemerintahan, merusak aset dan arsip-arsip pada Kantor Dinas Pekerjaan Umum Kabupaten Maros.

Melihat kejadian tersebut, maka Pemerintah Kabupaten Maros mengambil tindakan dalam upaya pencegahan bencana banjir yang mungkin akan terulang kembali. Tindak lanjut yang dilakukan adalah dengan meninggikan level lantai dasar pada gedung Kantor Dinas Pekerjaan Umum (PU). Meninggikan level ketinggian lantai hingga sekitar $80 \mathrm{~cm}$ sebagai bagian dari upaya pemerintah dalam penanganan bencana banjir tersebut menimbulkan efek pada bagian interior gedung, karena plafon gedung pada lantai dasar tidak mengalami perubahan ketinggian sedangkan lantai yang ditinggikan sekitar $80 \mathrm{~cm}$ membuat kenyamanan dalam gedung tersebut berkurang, karena kurangnya ketinggian ruang yang sudah tidak sesuai dengan standar kenyamanan pada gedung.

Dinas Pekerjaan Umum (PU) yang notabene banyak menangani urusan infrastruktur dan bangunan gedung tentunya dapat menjadi pilot project dalam memenuhi 
ruang-ruang yang sesuai standar gedung perkantoran dan standar kenyamanan pengguna bangunan. Permasalahan dalam pemenuhan standar gedung kantor berbenturan dengan ketersediaan anggaran dan kebutuhan ruang kantor yang mendesak pasca bencana banjir, sehingga rehab gedung kantor Dinas PU segera dilaksanakan.

Standar kenyamanan ruang dalam bangunan kantor salah satunya meliputi penataan ruang-ruang yang ada, baik di dalam bangunan maupun di luar bangunan. Pengaturan tata ruang kantor yang baik dapat membuat sistem pergerakan bekerja yang baik sehingga menciptakan pekerjaan yang efektif dan efisien dan memudahkan mencapai tujuan. Kondisi atau suasana kantor yang baik ditujukan untuk mendapatkan kenyamanan dan mendukung kelancaran efektivitas kerja pegawai yang ada di dalamnya.

Berbagai hasil penelitian tekait studi gedung perkantoran menemukan fakta bahwa faktor ketidakpuasan, tempat kerja berantakan, dan lingkungan fisik, berperan penting dalam berkurangnya bahkan menghilangkan produktivitas karyawan (Carnevale, 1992 dalam Zafani \& Rahardjo, 2016). Beberapa faktor yang berpengaruh pada kenyamanan dalam bekerja, salah satunya dapat ditemukan melalui desain lingkungan fisik gedung kantor yang baik (Maryati, dalam Wismonowati, 2012). Adapun faktor-faktor yang memengaruhi kenyamanan fisik antara lain: perabot kantor, dimensi perabot, dan penerangan.

Tiga hal yang sangat memengaruhi kenyamanan ruang, yaitu sistem kenyamanan termal, sistem akustik ruang dan sistem pencahayaan. Sistem yang dimaksud adalah berfungsinya berbagai faktor yang mendukung terwujudnya kenyamanan ruang. Pada upaya mencapai kenyamanan termal, terdapat beberapa faktor yang saling memengaruhi, di antaranya yaitu: luasan ruang, ketinggian ruang, bahan bangunan yang dimanfaatkan, posisi dan luas bukaan, vegetasi serta lingkungan sekitarnya. Dalam hal ini ketinggian ruang menjadi salah satu faktor yang memengaruhi sistem kenyamanan ruang kerja pada Dinas PU Kabupaten Maros.

Setiap elemen fisik pembentuk ruang harus didesain secara terintegrasi demi menghasilkan kondisi lingkungan kerja yang berkualitas, dengan tetap mempertimbangkan kepentingan fungsi dan estetika (Rayfield, 1958). Standar ruang dalam bangunan yang layak ditunjukkan pada Gambar 1.

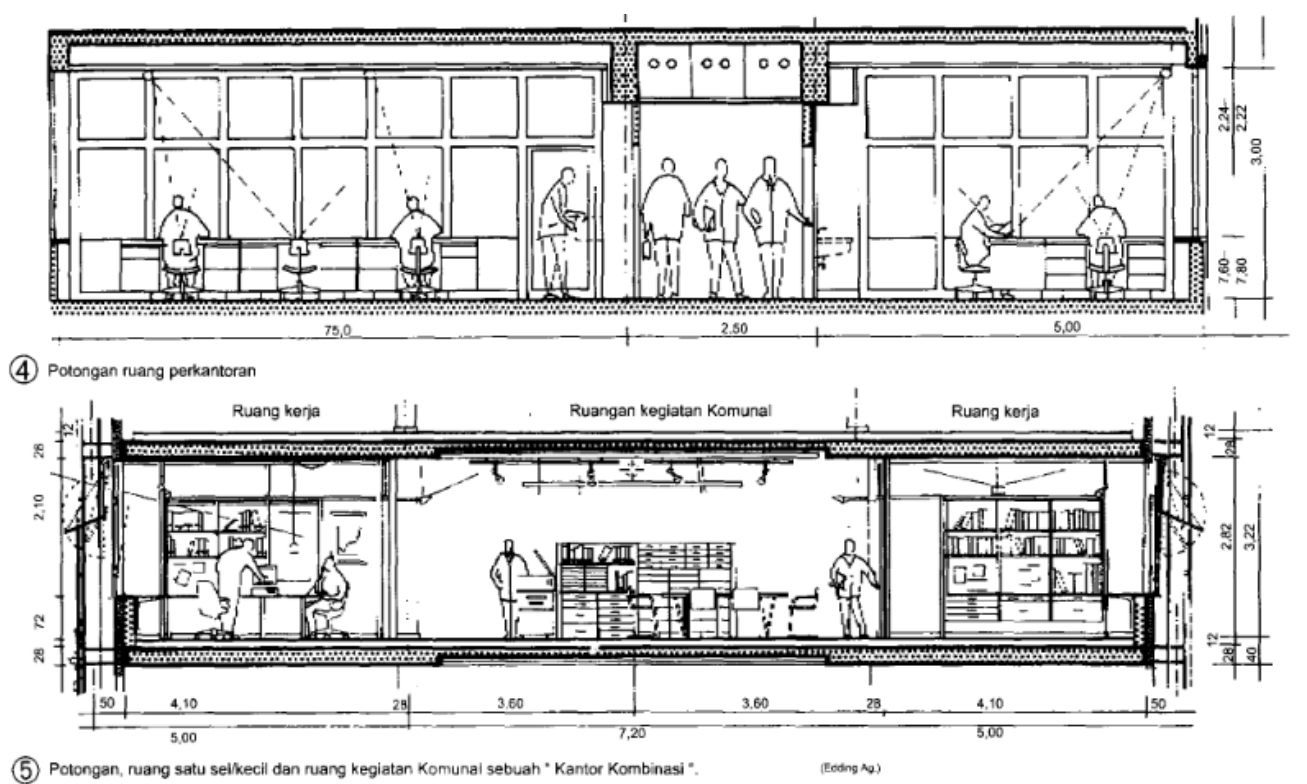

Gambar 1. Standar ruang dalam bangunan kantor (Neufert, 2004) 
Elemen bangunan dinding yang sering ditemukan pada bangunan kantor umumnya berupa panel. Selain itu ditemukan juga relocatable wall, yang merupakan alternatif dinding partisi dalam membatasi area privasi atau membagi ruang pada kantor open-plan. Dengan sistem relocatable mudah digeser atau dipindahkan, jenis dinding seperti ini efektif dan efisien dalam hal biaya dan waktu ketika perlu dilakukan renovasi. Sistem ini secara garis besar dibedakan menjadi dua macam. Yang pertama, moveable walls terdiri dari unit-unit individu. Dinding panel dibangun secara custom dan setiap panelnya berdiri sendiri, sehingga dapat diganti-ganti tanpa mengganggu panel yang ada di sebelahnya. Bentuk yang kedua adalah demounted wall system, yang didirikan pada jalur yang terdapat pada lantai dan langit-langit. Pada sistem ini, panel tidak dapat diganti tanpa menggeser panel di sebelahnya (Rayfield, 1958).

Elemen lantai merupakan bidang datar dimanfaatkan sebagai alas atau pijakan ruang dalam dimana manusia melakukan aktivitas. Rayfield (1958), mengatakan bahan bangunan lantai dikategorikan menjadi nonresilient (keras) yang terdiri dari jenis batuan, agglomerate, kayu, dan keramik, serta lantai kategori resilient (lunak) yang terdiri dari karpet, vinyl, dan linolium.

Plafon adalah suatu bidang yang berfungsi sebagai pelindung dan membentuk ruang di bawahnya. Terletak jauh di atas jangkauan tangan manusia, plafon memiliki peranan penting dalam menghasilkan keindahan visual terhadap ruang di bawahnya sekaligus sebagai pembatas ketinggian ruang. Efeknya dirasakan secara fisik, dan juga secara psikologi karena kesan perlindungan dan pernaungan yang diberikan (Ching, 1943) dan menurut Rossbach (2004) langit-langit yang rendah akan melemahkan energi manusia.

Tabel 1. Tingkat pencahayaan rata-rata yang direkomendasikan

\begin{tabular}{ll}
\hline Fungsi Ruangan & Tingkat Pencahayaan (lux) \\
\hline Perkantoran: & \\
\hline Ruang Direktur & 350 \\
\hline Ruang kerja & 350 \\
\hline Ruang komputer & 350 \\
\hline Ruang rapat & 300 \\
\hline Ruang gambar & 750 \\
\hline Gudang arsip & 150 \\
\hline Gudang arsip aktif & 300 \\
\hline Lembaga Pendidikan: & 250 \\
\hline Ruang kelas & 300 \\
\hline Perpustakaan & 500 \\
\hline Laboratorium & 750 \\
\hline Ruang gambar & 200 \\
\hline Kantin & \\
\hline Sumber: SNI 03-2000, Konservasi Energi Sistem Pencahayaan pada Bangunan Gedung
\end{tabular}

Tabel 1 menunjukan persyaratan tingkat pencahayaan dalam ruangan. Pencahayaan pada ruang kerja berfungsi dalam membantu kinerja pengguna ruang sebab dapat memberikan kejelasan dalam menjalankan aktivitas. Pencahayaan sangat berpengaruh pada efektivitas ruang kerja, gelap terangnya pencahayaan tergantung dari perencanaan desain bangunan itu sendiri. Menurut Lasa (2005), cahaya yang masuk ke dalam ruangan ada dua macam, yaitu:

1) Pencahayaan alami

Pencahayaan alami adalah penerangan yang ditimbulkan oleh cahaya matahari atau 
luminansi langit. Cahaya matahari yang masuk ke dalam ruang dan mengandung radiasi panas masuk dapat mengakibatkan kenaikan suhu ruangan. Cahaya alami masuk ke dalam ruangan melalui bukaan, ventilasi, atau celah dinding. Ukuran luas bukaan jendela dapat mempengaruhi intensitas cahaya yang masuk ke dalam ruangan.

2) Pencahayaan buatan

Pencahayaan buatan (artificial light) adalah segala bentuk cahaya yang bersumber dari alat yang dibuat oleh manusia. Contohnya: lampu pijar, lilin, dan lampu minyak tanah (Satwiko, 2005). Ada dua jenis penerangan buatan yaitu: (a) Penerangan umum langsung, yaitu sinar dipancarkan dari langit-langit ke setiap sudut ruang secara merata. Kap lampu berbetuk piring menimbulkan kesan luas dan formal, bagi ruangruang yang rendah untuk memberikan kesan luas; dan (b) Penerangan setempat, umumnya cahaya diarahkan ke arah tertentu saja. Penyatuan dan pengarahan cahaya dapat menggunakan kap lampu dengan reflektor khusus gerak maupun statis

\section{METODE PENELITIAN}

Jenis penelitian adalah penelitian kualitatif. Penelitian kualitatif adalah penelitian yang bersifat deskriptif dan cenderung menggunakan analisis. Sesuai dengan jenis penelitian, metode yang digunakan dalam penelitian ini adalah analisis deskriptif berdasarkan observasi lapangan dan wawancara, yang menjelaskan efek yang terjadi setelah penambahan level lantai setinggi $80 \mathrm{~cm}$ pasca banjir di Kabupaten Maros tanggal 22 Januari 2019 pada Kantor Dinas PU Kabupaten Maros terkait kesesuaian standar kenyamanan ruang kerja. Landasan teori dimanfaatkan sebagai pedoman agar fokus penelitian sesuai dengan fakta di lapangan. Instrument penelitian yang digunakan adalah kamera digital, rol meter, alat perlengkapan gambar dan pedoman wawancara.

\section{HASIL DAN PEMBAHASAN}

Lingkungan kerja adalah kehidupan sehari-hari yang dijalani meliputi psikis pekerja, psikis dan juga fisik dalam sebuah instansi. Hal ini nantinya akan memengaruhi kinerja seseorang atau karyawan dalam melaksanakan tugasnya. Manusia akan selalu bergantung pada keadaan atau lingkungan di sekitar dan keduanya saling berkaitan dan saling memengaruhi. Penambahan level ketinggian lantai pada Kantor Dinas PU Kabupaten Maros dalam upaya tindak lanjut pasca bencana banjir dapat dilihat pada Tabel 2.

Berdasarkan Tabel 2, dapat dilihat perbedaan ketinggian plafon pada tiap ruangan sangat signifikan. Jarak antar lantai dan plafon hanya setinggi 2,7 $\mathrm{m}$ dan jarak batas kepala orang dewasa dengan batas plafon hanya sekitar $90 \mathrm{~cm}$. Hal tersebut dapat menjadi salah satu faktor kurangnya tingkat kenyamanan ruang pada Kantor Dinas PU Kabupaten Maros, baik kenyamanan termal maupun kenyamanan psikologis pengguna ruangan. Perbedaaan ketinggian pada lemari kabinet juga terlihat setelah rehab bangunan kantor dilaksanakan. Level lantai yang ditinggikan $80 \mathrm{~cm}$ membuat lemari kabinet dapat mudah dijangkau oleh pegawai atau staf yang ada dalam lingkup kantor dan tidak membutuhkan alat bantu (kursi atau tangga) dalam mengambil dokumen yang ada di lemari kabinet tersebut.

Pencahayaan pada ruangan juga dapat dipengaruhi oleh tinggi plafon. Plafon yang tinggi pada suatu ruangan memerlukan lebih banyak pencahayaan, sedangkan ruangan yang memiliki plafon rendah membutuhkan pencahayaan yang relatif lebih kecil. Dari hasil pengamatan lapangan, jumlah titik lampu pada plafon dan bukaan jendela yang banyak dengan jarak plafon yang rendah akan membuat ruangan mendapatkan 
penerangan alami maupun buatan yang berlebihan. Meski demikian masih diperlukan penelitian mendalam terkait pencahayaan dalam ruangan pada kantor dinas PU Kabupaten Maros. Jarak plafon dengan lantai yang relatif rendah agar terkesan tinggi dapat disiasati dengan beberapa cara diantaranya:

1. Memberi efek tinggi pada ruang dengan menggunakan furnitur yang berukuran rendah;

2. Warna cat plafon senada atau warna sama dengan warna dinding agar plafon dan dinding terkesan menyatu;

3. Aplikasi warna terang, dikarenakan warna terang dapat memberi efek menambah jarak;

4. Menghindari penggunaan elemen-elemen dekorasi ruang/artwork yang beukuran besar.

Tabel 2. Renovasi gedung Kantor Dinas PU Kabupaten Maros

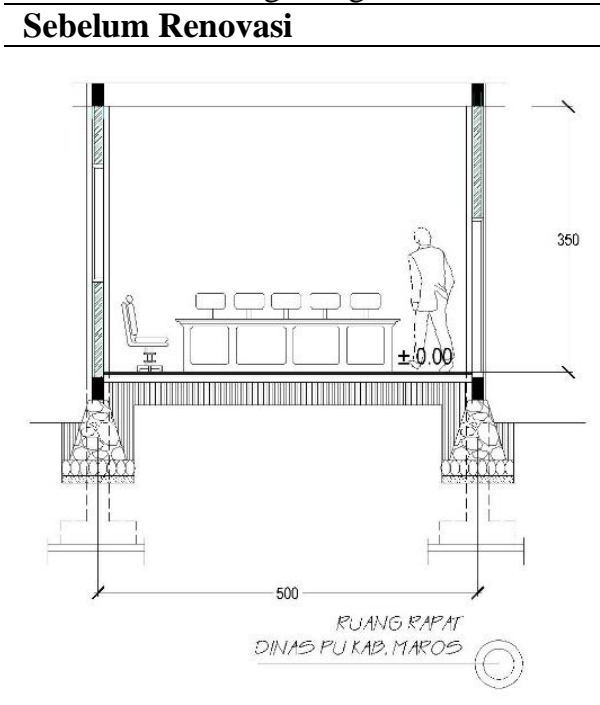

Jarak lantai dan plafon pada ruang rapat sebelum renovasi setinggi 3,5 meter.

\section{Sesudah Renovas}

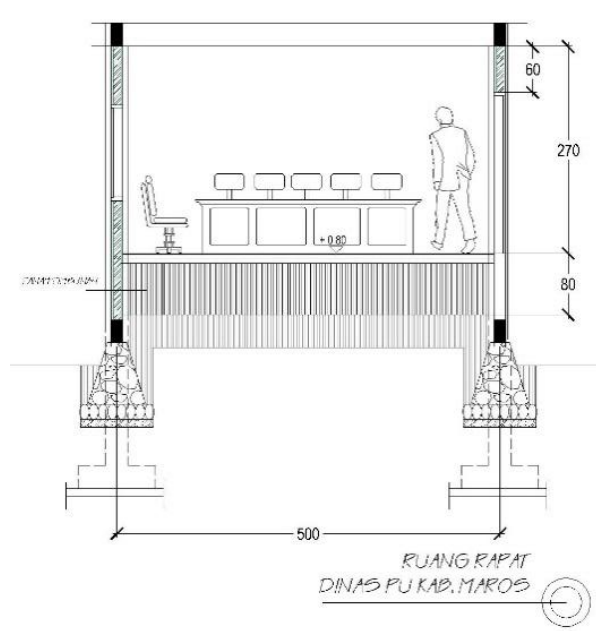

Jarak lantai dan plafon ruang rapat setelah renovasi setinggi 2,7 meter.

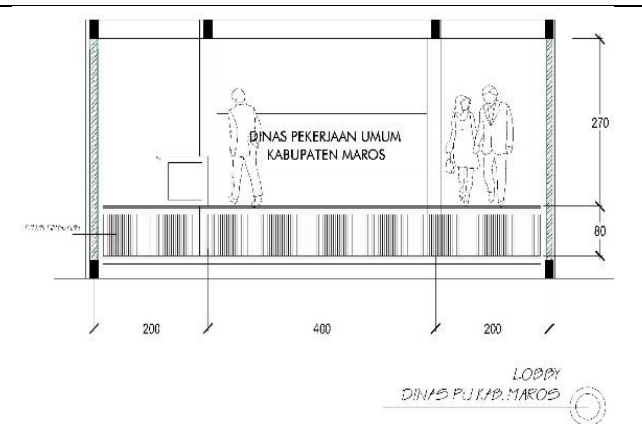

Jarak lantai dan plafon pada lobi setelah
Jarak lantai dan plafon pada lobi sebelum renovasi setinggi 3,5 meter. renovasi setinggi 2,7 meter.

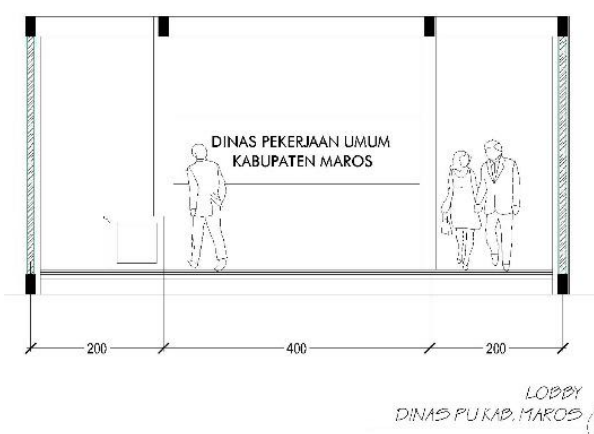




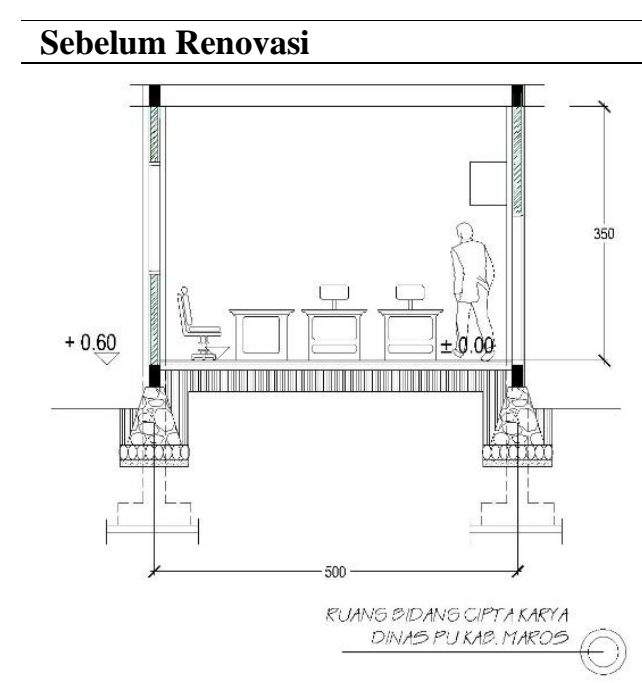

Jarak lantai dan plafon pada ruang Kepala Bidang dan Staf Cipta Karya sebelum renovasi setinggi 3,5 meter.

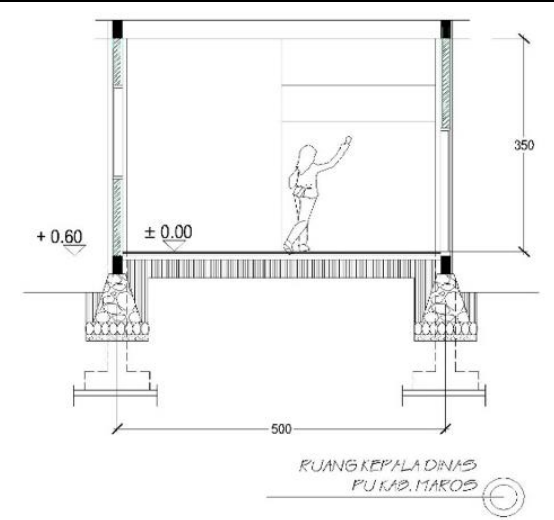

Jarak lantai dan plafon pada ruang Kepala Dinas sebelum renovasi setinggi 3,5 meter.

Lemari kabinet pada ruangan Kepala Dinas dijangkau dengan menggunakan alat bantu(tangga atau kursi).

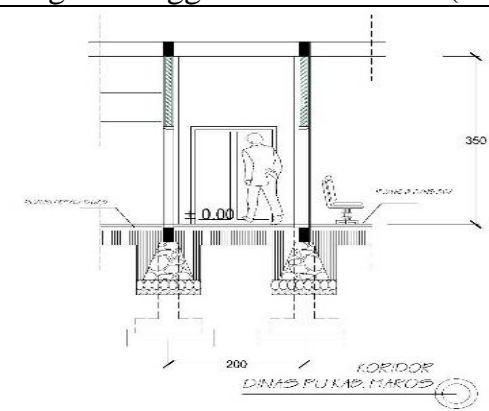

Jarak lantai dan plafon pada koridor sebelum renovasi setinggi 3,5 meter.

Jarak plafon dengan batas atas pintu $147 \mathrm{~cm}$.

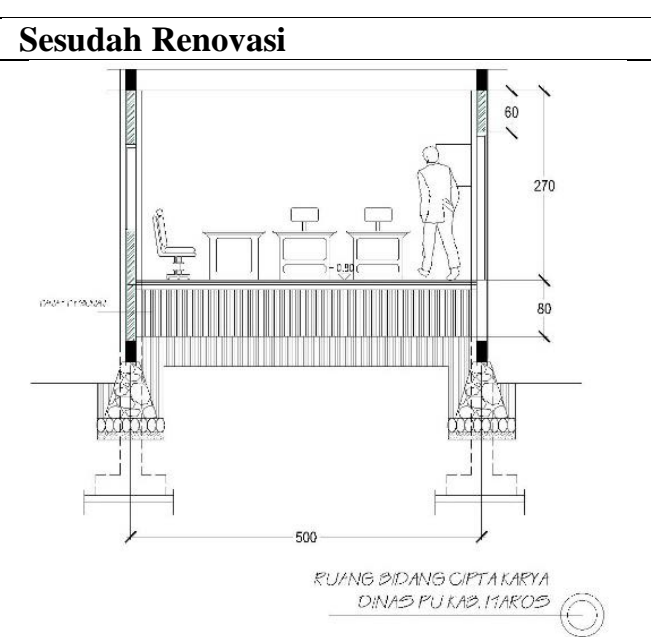

Jarak lantai dan plafon pada ruang Kepala Bidang dan Staf Cipta Karya setelah renovasi setinggi 2,7 meter.

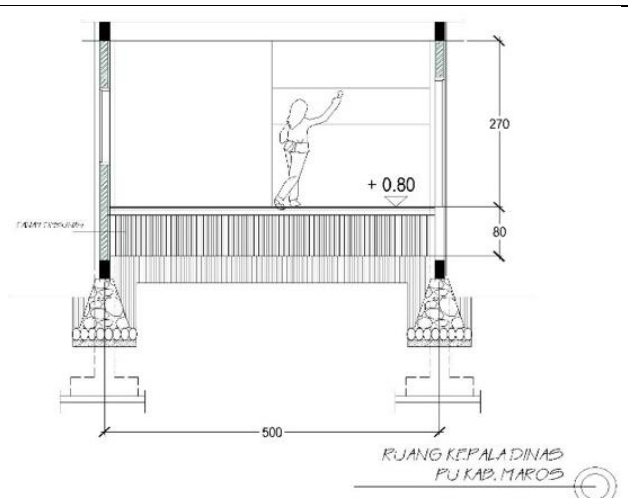

Jarak lantai dan plafon pada ruang Kepala Dinas setelah renovasi setinggi 2,7 meter. Lemari kabinet pada ruangan Kepala Dinas dijangkau dengan mudah dan tidak perlu menggunakan alat bantu (tangga atau kursi).

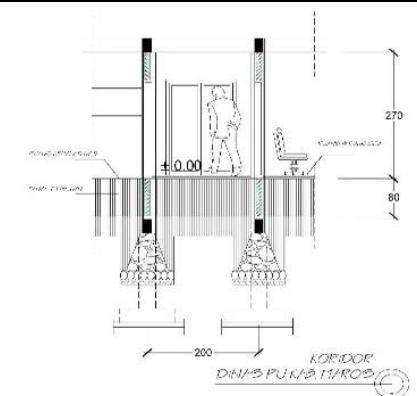

Jarak lantai dan plafon pada koridor setelah renovasi setinggi 2,7 meter.

Jarak plafon dengan batas atas pintu $60 \mathrm{~cm}$.

\section{KESIMPULAN}

Efek tindak lanjut Pemerintah Kabupaten Maros terhadap bangunan Kantor Dinas PU pasca bencana banjir di awal 2019 dengan meninggikan level lantai dasar bangunan kantor menyebabkan ruang yang ada di dalamnya memiliki ketinggian ruang 2,7 $\mathrm{m}$ yang dapat menjadi faktor kurangnya kenyamanan termal dan psikologi pengguna ruangan. 


\section{DAFTAR PUSTAKA}

Adi, S. (2013). Karakteristik bencana banjir bandang di Indonesia. Jurnal Sains dan Teknologi Indonesia, 15(1), 42-51.

Dinas PU Kab. Maros. (2019). Dokumen perencanaan rehab gedung Kantor Dinas PU Kab. Maros. Maros: Dinas PU Kab. Maros.

Hantono, D., \& D. Pramitasari (2018). Aspek perilaku manusia sebagai makhluk individu dan sosial pada ruang terbuka publik. National Academic Journal of Architecture, 5(2), 85-93. Doi. 10.24252/nature.v5i2a1.

Kristianto, T. A. (2016). Perancangan interior Kantor Pusat PT Pelindo 3 (Persero) dengan penerapan konsep seni nusantara untuk peningkatan efisiensi dan produktifitas kerja. Jurnal Desain Interior, 1(1), 61-68.

Lasa, H. S. (2005). Manajemen perpustakaan. Jakarta: Gama Media.

Nuefert, E. (1996). Data arsitek (Jilid 1). Jakarta: Erlangga.

Pratiwi, C. (2020). Perancangan interior kantor pada Perusahaan W Design. Jurnal FSD, 1(1), 1-12.

Rachmat, A. R. (2014). Faktor-faktor kerentanan yang berpengaruh terhadap bencana banjir di Kecamatan Manggala Kota Makassar. Jurnal Teknik ITS, 3(2), 178-183.

Santoso, E. B. (2013). Manajemen risiko bencana banjir kali lamong pada Kawasan Peri-Urban SurabayaGresik melalui pendekatan kelembagaan. Jurnal Penataan Ruang, 8(2), 48-59.

Thojib, J., \& M. S. Adhitama. (2013). Kenyaman visual melalui pencahayaan alami pada kantor. Jurnal Ruas, 11(2), 10-15.

Wismonowati, D. (2012). Kajian Tingkat Kenyamanan Fisik Ruang Dalam Berdasarkan Persepsi Pengguna. [Skripsi]. Semarang: Universitas Negeri Semarang.

Zavani, M. N., \& S. Rahardjo. (2016). Pengaruh setting elemen fisik ruang kantor terhadap produktivitas kerja karyawan. Jurnal Desain Interior \& Desain Produk, 1(1), 34-36. 